\title{
ADSORBED LAYERS OF ALBUMIN AND FIBRINOGEN ON POLYSTYRENE, PROBED BY CONTACT ANGLE MEASUREMENTS
}

\author{
A. VAN DER SCHEER, D. BARGEMAN, H. G. KOETSIER \\ and C. A. SMOLDERS \\ Twente University of Technology, Enschede, The Netherlands
}

\section{SYNOPSIS}

Earlier measurements of paraffin oil (PO) - water contact angles on protein layers [human serum albumin (HSA) or human fibrinogen (HFb)] adsorbed on polystyrene (PS) showed that HSA could be transferred from the PS/water to the PO/water interface by a passing POwater front, while $\mathrm{HFb}$ could not. Interfacial association of adsorbed HFb molecules was adopted as an explanation for the irreversible localization of $\mathrm{HFb}$ at the PS surface. In the present work it is shown that aggregation by a heat treatment of adsorbed HSA molecules also causes an irreversible localization of the HSA at the PS surface. It is shown that advancing and receding PO-water contact angles on HSA-coated PS substrates have practically the same value. Variation of $\mathrm{pH}$ and $\mathrm{NaCl}$ concentration hardly shows any effect on these contact angles, indicating that in all cases the HSA coating behaves the same. The advancing and receding PO-water contact angles on HFb-coated substrates differ greatly. In analogy with ElShimi and Goddard we conclude that the natural HFb coating is able to adopt and retain a configuration compatible with the immediate environment.

\section{INTRODUCTION}

Early work by Vroman [1] suggests that there is a difference in wetting behavior of different proteins, adsorbed on glass or polymer surfaces. Vroman's treatment was a rather qualitative one: adsorbed protein layers had been dried in air completely and wetting was judged by vapor (droplet) condensation.

In a previous paper [2] we have worked out protein layer wettability in a more quantitative way. It was shown that the behavior of an oil drop on a protein-coated polystyrene (PS) substrate immersed in buffer solution depends on the type of protein used for the coating. On a PS substrate coated with human serum albumin (HSA) the contact angle, measured through the oil phase, decreased slowly from $\sim 180^{\circ}$ to $50 \pm 5^{\circ}$. The contact angle on a PS substrate coated with human fibrinogen $(\mathrm{HFb})$ reached a final value of $130 \pm 10^{\circ}$. The difference between the contact angles on the protein-coated substrates appeared to be the result of a difference in the transfer of the proteins when a three-phase contact line is passing. HSA molecules are transferred from the PS/water interface to the oil/water interface leading to a large decrease of the $\theta$ value in that case. The irreversible localization of $\mathrm{HFb}$ at the PS surface, possibly due to interfacial association, opposes such a large decrease in contact angle for the oil drop. 
In the present article further evidence is presented for the statement that a layer of associated protein molecules will not be transferred from the PS/water interface to the oil/water interface by a passing oil-water front. From adsorption studies [3] it is known that protein adsorption is influenced by $\mathrm{pH}$ and salt concentration. The influence of these two parameters on the contact angle is studied for both proteins. The results hitherto obtained have been measured for an advancing oil/water interface. Measurements of contact angles for a receding oil/water interface have now been performed to get more information about the character of the adsorbed protein layers.

\section{EXPERIMENTAL}

\section{Materials}

Human serum albumin (HSA), crystallized, was obtained from Pierce Chemicals, Prod. No. 30430. Human fibrinogen (HFb), >90\% clottable, was obtained from AB Kabi, Stockholm. Polystyrene (PS) was obtained from Pressure Chemical Company, Pittsburgh, Mellon Institute, Special Polystyrene standard. $M_{w}=670000 M_{w} / M_{n}=1.15$, lot No. 13a. Paraffin oil (PO) was obtained from Baker Chemicals, Deventer, Holland. Before use it was twice purified by percolating over an $\mathrm{Al}_{2} \mathrm{O}_{3}$ column.

Buffer solutions were prepared by adding an aqueous solution of $0.01 \mathrm{M}$ $\mathrm{KH}_{2} \mathrm{PO}_{4}$ and the proper amount of $\mathrm{NaCl}$ to an aqueous solution of $0.01 \mathrm{M}$ $\mathrm{NaOH}$ and the same amount of $\mathrm{NaCl}$ until a pH of 7.4 was reached. Other $\mathrm{pH}$ values were obtained by adding $\mathrm{NaOH}$ or $\mathrm{HCl}$ until the desired value was reached.

All protein solutions were stored at a temperature of $277 \mathrm{~K}$, under sterile conditions, and they were used within one week after preparation. All chemicals used were analytical grade.

\section{Methods: Contact-Angle Measurements}

Polystyrene (PS) substrates were obtained by dipping glass surfaces in a solution of PS in toluene (7\%) and drying them afterwards. The dipping procedure was repeated three times. After the third time, the substrate was dried for 1 day at room temperature. Drying for a week at a temperature above the glass transition of PS did not give different contact-angle results. Subsequently the substrates were conditioned in a buffer solution for 1 day.

Then the substrate was placed in a fresh buffer solution, after which a concentrated protein solution was added until the desired protein concentration of $0.5 \mathrm{~kg} \mathrm{~m}^{-3}$ was reached. After $1 \mathrm{hr}$ the protein solution was washed away by a buffer solution containing no protein. The replacement 
of protein solution is a necessary step in the procedure, first to be sure that the oil-water interfacial tension during contact-angle measurements does not change due to adsorption of protein from the solution and secondly to prevent contact between the substrate and the protein solution/air interface after the adsorption step. If this contact occurs the adsorbed and probably denaturated protein layer at the air/solution interface may be deposited on the substrate as a kind of Blodgett layer $[4,5]$.

Subsequently the substrate was taken out, put directly into a cell containing buffer solution, and placed on a platform in the contact-angle measurements set up. Using a glass capillary, a small drop of paraffin oil (diameter $\sim 0.3 \times 10^{-3} \mathrm{~m}$ ) was brought under the substrate. The contact angle $\theta_{A}$ of this drop with the substrate was determined from the dimensions of the drop (Bargeman [6], see Fig. 1). A necessary condition for this method is that the shape of the drop is not influenced by gravity (small drops should be used).

For measurements of the receding contact angle through the oil phase $\theta_{R}$ the substrate was taken out of the buffer solution, swept off, and then placed in a cell containing paraffin oil. Using a glass capillary a small drop of buffer solution (diameter $\sim 0.3 \times 10^{-3} \mathrm{~m}$ ) was dropped on the substrate. The contact angle of this drop, which is equal to $180^{\circ}-\theta_{R}$, was determined in the same way as described above.

Heat denaturation of adsorbed protein layers was performed prior to immersion in the cell, by placing the substrate in a buffer solution at $343 \mathrm{~K}$ for $\sim 10^{3} \mathrm{sec}$.

\section{RESULTS}

All adsorption experiments have been performed at protein concentrations of $0.5 \mathrm{~kg} \mathrm{~m}^{-3}$ in buffer solutions at different $\mathrm{pH}$ values and $\mathrm{NaCl}$ concentrations.

Advancing contact angles $\theta_{A}$ obtained with paraffin oil drops on HSAcoated substrates immersed in buffer solutions at different $\mathrm{pH}$ values and $\mathrm{NaCl}$ concentrations are given in Table $\mathrm{I}$.

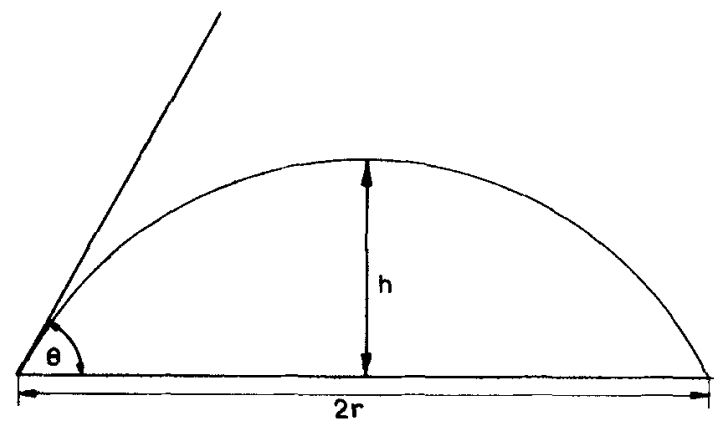

FIG. 1. $\sin \theta=2 \mathrm{hr} /\left(h^{2}+r^{2}\right)$. 
TABLE I

Advancing Contact Angles of Oil Drops on HSA-Coated Substrates

\begin{tabular}{|l|c|c|c|}
\hline $\mathrm{pH}$ & $\begin{array}{c}{[\mathrm{NaCl}]} \\
\text { kmol. } \mathrm{m}^{-3}\end{array}$ & $\begin{array}{l}{ }_{\mathrm{A}}(\text { initial }) \\
\text { (within } 30 \mathrm{sec} .)\end{array}$ & ${ }_{\mathrm{A}}$ (final) \\
\hline 2.5 & 0 & $45^{\circ}$ & $45^{\circ}$ \\
4.9 & 0 & $145^{\circ}$ & $65^{\circ}$ \\
9.0 & 0 & $130^{\circ}$ & $45^{\circ}$ \\
2.5 & 0.15 & $142^{\circ}$ & $42^{\circ}$ \\
4.9 & 0.15 & $145^{\circ}$ & $62^{\circ}$ \\
7.4 & 0.15 & $160^{\circ}$ & $55^{\circ}$ \\
9.0 & 0.15 & $160^{\circ}$ & $75^{\circ}$ \\
\hline
\end{tabular}

In Table I $\theta_{A}$ (initial) is the first value of the contact angle that could be measured after deposition of the PO drop on the substrate (10-30 sec after deposition). The final value of the contact angle $\theta_{A}$ (final) has been measured after $\sim 6 \times 10^{4} \mathrm{sec}$. Actually this last value has been reached generally within $10^{3} \mathrm{sec}$ after deposition. Results obtained on HFb-coated substrates for different $\mathrm{pH}$ values and $\mathrm{NaCl}$ concentrations are shown in Table II.

Measurements on heat-denatured HSA coatings on PS substrates have been performed at different $\mathrm{pH}$ values. The $\theta_{A}$ values obtained are shown in Table III.

TABLE II

Advancing Contact Angles of Oil Drops on HFb-Coated Substrates

\begin{tabular}{|c|c|c|c|}
\hline $\mathrm{pH}$ & $\begin{array}{l}{[\mathrm{NaCl}]} \\
\mathrm{kmol} \cdot \mathrm{m}^{-3}\end{array}$ & $\begin{array}{l}{ }^{\theta} \mathrm{A}(\text { initial }) \\
(\text { within } 30 \text { sec })\end{array}$ & ${ }^{\theta} \mathrm{A}($ fina $)$ \\
\hline 3 & 0 & 140 & 102 \\
\hline 7.4 & 0 & 165 & 160 \\
\hline 9.5 & 0 & 165 & 162 \\
\hline 3 & 0.05 & 150 & 120 \\
\hline 7.4 & 0.15 & 155 & 140 \\
\hline 9.5 & 0.15 & 165 & 155 \\
\hline
\end{tabular}


TABLE III

Advancing Contact Angles of Oil Drops on Heat-Treated HSA Coatings

\begin{tabular}{|c|c|c|c|}
\hline $\mathrm{pH}$ & $\begin{array}{c}{[\mathrm{NaCl}]} \\
\mathrm{kmol} . \mathrm{m}^{-3}\end{array}$ & $\begin{array}{c}{ }_{\mathrm{A}} \text { (initial) } \\
\text { (within 30 sec) }\end{array}$ & ${ }_{\mathrm{A}}$ (final) \\
\hline 2.5 & 0.15 & $60^{\circ}$ & $45^{\circ}$ \\
4.9 & 0.15 & $150^{\circ}$ & $120^{\circ}$ \\
7.4 & 0.15 & $150^{\circ}$ & $140^{\circ}$ \\
9.0 & 0.15 & $140^{\circ}$ & $120^{\circ}$ \\
\hline
\end{tabular}

The contact angles $\theta_{R}$ for the oil phase obtained with drops of buffer solution on HSA-coated substrates immersed in PO ("inverse system") at different $\mathrm{pH}$ values and $\mathrm{NaCl}$ concentrations are given in Table IV.

The results from the measurements in the inverse system on HFb-coated substrates at different $\mathrm{pH}$ values and $\mathrm{NaCl}$ concentrations are collected at Table V.

The contact angle $\theta_{A}$ was also measured in the inverse system by decreasing the volume of the drops of buffer solution until the $\mathrm{PO} /$ water boundary on the substrate started to move. For the HSA-coated substrate this contact angle $\theta_{A}$ was practically the same as the observed value of $\theta_{R}$. On the other hand, the volume of a drop of buffer solution $(\mathrm{pH}=7.4)$ on a HFbcoated substrate could deliberately be decreased without the effect that the $\mathrm{PO} /$ water boundary started to move. This could be continued until a $\theta$

TABLE IV

Receding Contact Angles for the Oil Phase on HSA-Coated Substrates ("Inverse System")

\begin{tabular}{|c|c|c|c|}
\hline $\mathrm{pH}$ & $\begin{array}{c}{[\mathrm{iaCl}]} \\
\mathrm{kmol} . \mathrm{m}^{-3}\end{array}$ & $\begin{array}{l}\theta_{\mathrm{R}} \text { (initial) } \\
\text { (within 30 sec) }\end{array}$ & ${ }_{\mathrm{R}}$ (final) \\
\hline 2.5 & 0 & $60^{\circ}$ & $60^{\circ}$ \\
4.9 & 0 & $75^{\circ}$ & $65^{\circ}$ \\
9.0 & 0 & $67^{\circ}$ & $50^{\circ}$ \\
2.5 & 0.15 & $63^{\circ}$ & $63^{\circ}$ \\
4.9 & 0.15 & $72^{\circ}$ & $70^{\circ}$ \\
9.0 & 0.15 & $58^{\circ}$ & $58^{\circ}$ \\
\hline
\end{tabular}


TABLE V

Receding Contact Angles for the Oil Phase on HFb-Coated Substrates ("Inverse System")

\begin{tabular}{|c|c|c|c|}
\hline $\mathrm{pH}$ & $\begin{array}{c}{[\mathrm{NaCl}]} \\
\mathrm{kmol} . \mathrm{m}^{-3}\end{array}$ & $\begin{array}{l}{ }_{\mathrm{R}}(\text { initial }) \\
\text { (within 30 sec) }\end{array}$ & ${ }_{\mathrm{R}}$ (final) \\
\hline 3.0 & 0 & $80^{\circ}$ & $85^{\circ}$ \\
7.4 & 0 & $82^{\circ}$ & $83^{\circ}$ \\
9.0 & 0 & $90^{\circ}$ & $90^{\circ}$ \\
3.0 & 0.05 & $80^{\circ}$ & $80^{\circ}$ \\
7.4 & 0.15 & $90^{\circ}$ & $90^{\circ}$ \\
9.0 & 0.15 & $86^{\circ}$ & $86^{\circ}$ \\
\hline
\end{tabular}

value $<20^{\circ}$ measured over the droplet phase was reached, which means that for this measuring technique $\theta_{A}>160^{\circ}$.

\section{DISCUSSION}

\section{The Effect of pH and Salt on Results for HSA Coatings}

From the influence of $\mathrm{pH}$ and salt concentration on the maximum adsorption of HSA on PS [3] it was expected that there might be a difference in behavior between a layer of HSA adsorbed at its isoelectric point (iep) ( $\mathrm{pH}=4.9$ ) and layers adsorbed at $\mathrm{pH}$ values far away from this iep. Table I shows the influence of $\mathrm{pH}$ and $\mathrm{NaCl}$ concentration on the $\theta_{A}$ values on HSA-coated PS substrates. It appears that the influence on the final $\theta_{A}$ values is very small. In a previous paper [2] we derived an equation to estimate the value of the polar interaction term $I_{s}(p)_{w}$, between an adsorbed protein layer and the aqueuus phase. It was assumed that no turnover of the protein molecules from the PS substrate to the $\mathrm{PO} /$ water interface takes place.

$$
I_{s(p) w}=\gamma_{o, w}\left(\cos \theta_{a}-\cos \theta_{b}\right)-(0 \text { to } 5) \mathrm{mN} \mathrm{m}^{-1}
$$

where $\theta_{a}$ is the $30^{\circ} \pm 3^{\circ}$ contact angle for an oil drop on the bare substrate immersed in water (buffer), $\theta_{b}$ is the contact angle for an oil drop measured on the protein-coated substrate in water (buffer), and $\gamma_{a, w}$ is the $50 \mathrm{mN} \mathrm{m}^{-1}$ interfacial tension at the $\mathrm{PO} /$ water interface.

Introduction of the $\theta_{A}$ (final) values in eq. (1) gives a polar interaction term of $0<I_{s(p) w}<25 \mathrm{mN} \mathrm{m}^{-1}$ for HSA coatings. This value is much lower than expected for the polar interaction between a highly swollen pro- 
tein layer and water. This would indicate that in these measurements turnover of the HSA molecules from the PS/water interface to the PO/water interface takes place. From the difference between $\theta_{A}$ (initial) and $\theta_{A}$ (final) it is clear that at $\mathrm{pH}=4.9$ and $9.0 \theta_{A}$ is time dependent and at $\mathrm{pH}=$ 2.5 the final value of $\theta_{A}$ has been reached immediately. The very fast turnover of adsorbed HSA molecules at this $\mathrm{pH}$ might be due to the fact that the HSA molecules have a different conformation at this $\mathrm{pH}$. At $\mathrm{pH}$ values between 4.9 and 2.5 the so-called $\mathrm{N}-\mathrm{F}$ transition of the molecule is observed [7].

\section{Effect of pH and Salt on Results for HFb Coatings}

The values for $\theta_{A}$ on $H F b$-coated substrates at different $\mathrm{pH}$ values and $\mathrm{NaCl}$ concentrations are shown in Table II. In this case no experiments have been performed at the isoelectric point of the $\mathrm{HFb}(\mathrm{pH}=5.5)$ because $\mathrm{HFb}$ solutions are not stable at their iep. The experimental conditions were chosen such that $\mathrm{HFb}$ adsorption took place from clear solutions.

It is shown (Table II) that there is hardly any influence of $\mathrm{pH}$ and salt concentration on the $\theta_{A}$ values on the HFb-coated substrates. Using eq. (1) and the $\theta_{A}$ (final) values the polar interaction term between the protein and the aqueous phase is $80<I_{s}(p)_{w}<90 \mathrm{mN} \mathrm{m}^{-1}$ (for $\mathrm{HFb}$ coatings) for all measurements, except those at $\mathrm{pH}=3.0$. At this $\mathrm{pH}=3.0$ the polar interaction is calculated to be $50<I_{s}(\rho) w<70 \mathrm{mN} \mathrm{m}^{-1}$. The somewhat lower value of $I_{s(p) w}$ at low $\mathrm{pH}$ may be due to a reduced polar contribution of the $\mathrm{HFb}$ coating to the $\mathrm{PO} / \mathrm{HFb}$ interfacial tension resulting from reconformation of the $\mathrm{HFb}$ molecules.

In our first paper [2] we postulated that the difference in behavior between an oil drop on a HFb-coated and a HSA-coated substrate is caused by association of the adsorbed HFb molecules, whereas HSA molecules do not associate. The interfacial association of the $\mathrm{HFb}$ molecules prevents the protein layer from being transferred from the PS substrate to the $\mathrm{PO} /$ water interface. It is known [7] that at temperatures above $333 \mathrm{~K}$ HSA molecules do associate in solution. Therefore HSA-coated substrates were incubated for about $10^{3} \mathrm{sec}$ at $343 \mathrm{~K}$ in protein-free buffer solutions in order to produce a substrate coated with associated HSA molecules.

The results of contact angle $\left(\theta_{A}\right)$ measurements on these substrates are shown in Table III. The observed $\theta_{A}$ values are similar to those found for $\mathrm{HFb}$-coated substrates. This indicates that adsorbed, associated HSA molecules are not transferred either from the PS substrate to the PO/water interface by a passing oil-water front. HSA-coated substrates which have been incubated at $\mathrm{pH}=2.5$ show a different behavior. These substrates still show the same $\theta_{A}$ value as untreated HSA-coated substrates. Some qualitative experiments have been performed to obtain an explanation for this phenomenon. HSA solutions at the investigated pH-values (2.5, 7.4, 9.0) were incubated for about $10^{3} \mathrm{sec}$ at $343 \mathrm{~K}$. After incubation the 
solutions with a pH value of 7.4 and 9.0 were cloudy due to HSA association, but the solution at $\mathrm{pH}=2.5$ was still clear, indicating that at this $\mathrm{pH}$ aggregation does not take place. More accurate experiments on the determination of the aggregation are in progress (poly-acrylgel electrophoresis).

\section{Receding Contact Angles (Inverse Systems)}

Tables IV and V show results for contact-angle measurements in inverse systems. These contact angles $\theta_{R}$ are obtained from a receding PO phase.

Comparison of contact angles on HSA-coated substrates in Table $I$ and Table IV shows an insignificant difference between $\theta_{A}$ (final) and $\theta_{R}$ (final). The large difference between the initial values of $\theta_{A}$ and $\theta_{R}$ results from the fact that in the inverse system there is no time dependence for $\theta_{R}$.

The instantaneously obtained $\theta_{R}$ (final) value can be explained by assuming that upon immersion of the protein-coated substrate in PO the thin aqueous film on the PS substrate breaks up in tiny droplets. The oil phase thus is in direct contact with the PS surface for the greater part of the interface and most of the HSA molecules are accumulated at the oil-water interface of the droplets. When a drop of water is deposited on such a substrate it will be obvious that the tiny droplets will merge instantaneously with the advancing water drop and the HSA molecules will be accumulated at the oil-water interface.

In this way the final situation at the three-phase boundary will be almost identical to that in the normal system, after turnover of the protein molecules. The observation that the contact angle in the inverse system does not change significantly upon decreasing the volume of the water drop is in agreement with the above picture.

Table $\mathrm{V}$ shows the results of measurements on $\mathrm{HFb}$-coated substrates in the reverse system. Comparison of these $\theta_{R}$ values with $\theta_{A}$ measurements in Table II on $\mathrm{HFb}$-coated substrates, shows that in both cases hardly any time dependence occurs. However, there is a large difference between $\theta_{A}$ and $\theta_{R}$ on these substrates. A similar feature has been found by El-Shimi and Goddard [8] for contact angles on bovine hoof keratin. For advancing oil phase they observed a $\theta_{A}$ of $>170^{\circ}$. A $\theta_{R}$ value of $30^{\circ}$ was found when the substrate was first treated with mineral oil. They conclude that this behavior is governed by the history of exposure to the contacting liquid, which seems to be a specific feature of natural surfaces. In analogy we conclude that the $\mathrm{HFb}$ coating is able to adopt and retain a configuration compatible with the immediate environment. The observation that the contact angle in the inverse system changes drastically (from $90^{\circ}$ to $>160^{\circ}$ ) when decreasing the volume of the drop is in agreement with this conclusion. 


\section{REFERENCES}

[1] L. Vroman, Nature, 196, 476 (1962).

[2] A. van der Scheer and C. A. Smolders, J. Colloid Interface Sci. , 63, 7 (1978).

[3] W. Norde, "Proteins at Interfaces," Thesis, Communications Agricultural University Wageningen, The Netherlands, 76-6, 1976.

[4] S. Ghosh, K. Breese and H. B. Bull, J. Colloid Interface Sci, 19, 457 (1964).

[5] K. B. Blodgett, J. Am. Chem. Soc., 57, 1007 (1935).

[6] D. Bargeman, J. Colloid Interface Sci., 40, 344 (1972),

[7] W. G. M. Braam, "On the Structure of the Albumin Molecule," Thesis, University of Nijmegen, The Netherlands, 1972.

[8] A. El-Shimi and E. W. Goddard, J. Colloid Interface Sci, 48, 249 (1974). 